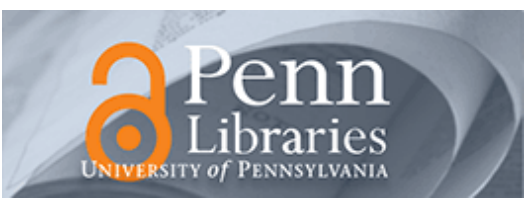

\author{
University of Pennsylvania \\ ScholarlyCommons
}

PARC Departmental Papers

Population Aging Research Center

September 2005

\title{
Using Anthropometric Indicators for Mexicans in the United States and Mexico to Understand the Selection of Migrants and the "Hispanic Paradox"
}

\author{
Eileen M. Crimmins \\ University of Southern California \\ Beth J. Soldo \\ University of Pennsylvania, bsoldo@pop.upenn.edu \\ Jung Ki Kim \\ University of Southern California \\ Dawn Alley \\ University of Pennsylvania, alley@wharton.upenn.edu
}

Follow this and additional works at: https://repository.upenn.edu/parc_pubs

Crimmins, Eileen M.; Soldo, Beth J.; Kim, Jung Ki; and Alley, Dawn, "Using Anthropometric Indicators for Mexicans in the United States and Mexico to Understand the Selection of Migrants and the "Hispanic Paradox"'" (2005). PARC Departmental Papers. 2.

https://repository.upenn.edu/parc_pubs/2

Postprint version. Published in Social Biology, Volume 52, Issue 3/4, Fall 2005, pages 164-177

This paper is posted at ScholarlyCommons. https://repository.upenn.edu/parc_pubs/2

For more information, please contact repository@pobox.upenn.edu. 


\title{
Using Anthropometric Indicators for Mexicans in the United States and Mexico to Understand the Selection of Migrants and the "Hispanic Paradox"
}

\begin{abstract}
Anthropometric measures including height provide an indication of childhood health that allows exploration of relationships between early life circumstances and adult health. Height can also be used to provide some indication of how early life health is related to selection of migrants and the Hispanic paradox in the United States. This article joins information on persons of Mexican nativity ages 50 and older in the United States collected in the National Health and Nutrition Examination Survey IV (NHANES IV 1999-2002) with a national sample of persons of the same age living in Mexico from the Mexican Health and Aging Survey (MHAS 2001) to examine relationships between height, education, migration, and late-life health. Mexican immigrants to the United States are selected for greater height and a high school, rather than higher or lower, education. Return migrants from the United States to Mexico are shorter than those who stay. Height is related to a number of indicators of adult health. Results support a role for selection in the Hispanic paradox and demonstrate the importance of education and childhood health as determinants of late-life health in both Mexico and the United States.
\end{abstract}

\section{Keywords}

anthropometric measures, childhood health, Hispanic paradox, migrants, NHANES, MHAS, indicators, adult health

\section{Comments}

Postprint version. Published in Social Biology, Volume 52, Issue 3/4, Fall 2005, pages 164-177 


\title{
Using Anthropometric Indicators for Mexicans in the United States and Mexico to Understand the Selection of Migrants and the "Hispanic Paradox"
}

Eileen M. Crimmins ${ }^{\mathrm{a} *}$; Beth J. Soldo ${ }^{\mathrm{b}}$; Jung Ki Kim ${ }^{\mathrm{a}}$; and Dawn E. Alley

"Leonard Davis School of Gerontology, Andrus Gerontology Center. University of Southern California, Los Angeles, CA, USA; ${ }^{b}$ Population Aging Research Center, University of Pennsylvania, Philadelphia, PA, USA; 'Robert Wood Johnson Health and Society Scholars Program. University of Pennsylvania, Philadelphia, PA, USA

\begin{abstract}
Anthropometric measures including height provide an indication of childhood health that allows exploration of relationships between early life circumstances and adult health. Height can also be used to provide some indication of how early life health is related to selection of migrants and the Hispanic paradox in the United States. This article joins information on persons of Mexican nativity ages 50 and older in the United States collected in the National Health and Nutrition Examination Survey IV (NHANES IV 1999-2002) with a national sample of persons of the same age living in Mexico from the Mexican Health and Aging Survey (MHAS 2001) to examine relationships between height, education, migration, and late-life health. Mexican immigrants to the United States are selected for greater height and a high school, rather than higher or lower, education. Return migrants from the United States to Mexico are shorter than those who stay. Height is related to a number of indicators of adult health. Results support a role for selection in the Hispanic paradox and demonstrate the importance of education and childhood health as determinants of late-life health in both Mexico and the United States.
\end{abstract}

A growing proportion of persons in the United States identify themselves as of Hispanic or Latino origin. In 2000, more than 35.3 million Hispanics made up $12.5 \%$ of the total U.S. population (U.S. Census Bureau, n.d.). Over half of the Hispanic population in 2000 consisted of immigrants who had entered the United States in the past 10 years (Ramirez and de la Cruz, 2003). Hispanics in the United States have been reported to have better health and lower mortality than expected given their low social and economic status

*Address correspondence to: Fïleen M. Crimunins, Andrus Geromtology Center, University of Southern California, Los Angeles, CA 90089-0191, USA. F.-mail: crimmin (a) usc.edu
(Cho, Frisbie, and Rogers, 2004; Elo et al., 2004; Singh and Miller, 2004). This better than expected health has been termed the Hispanic paradox.

However, researchers have argued recently that the paradox may not be so paradoxical in a population heavily weighted with immigrants (Jasso et al., 2004; Palloni and Arias, 2004; Palloni and Ewbank, 2004; Palloni and Morenoff, 2001). Two explanations for the Hispanic paradox rest on assumptions about selection of migrants into, and out of, the United States by health status. The healthy migrant hypothesis suggests that healthier Hispanics immigrate to the United States (Sorlic et al., 1993; Abraido-Lanza et al., 1999). This selection 
of healthy persons from the sending population can improve the level of health in the receiving population. Another hypothesis, termed the returning-salmon hypothesis, posits that some sick migrants return home, again improving the health of the population they leave (Abraido-Lanza et al., 1999; Palloni and Arias, 2004).

Because initial migration most commonly takes place in young adulthood, understanding the selection process requires data on health at a young age. When explicit information on one's health, diet and nutrition, health behaviors, and living conditions at younger ages is not available, indirect or proxy measures of childhood conditions may be derived from anthropometric data collected later in life (Gunnell, 2002). Studies have suggested that height and leg length, which are relatively fixed at a young age, can provide important summary indicators of nutritional and health status in early life (Davey Smith et al., 2000; Wadsworth et al., 2002).

In terms of understanding the Hispanic paradox in the United States, Mexican Americans are of particular interest because they comprise about $70 \%$ of the total Hispanic population, they contribute to the majority of current growth in the Hispanic population, and they have lower sociocconomic status (SES) than both non-Hispanic Whites and other major Latino populations in the United States (Ramirez and de la Cruz, 2003). In this article we use data representative of persons age 50 and older of Mexican origin living in both Mexico and the United States to examine differences between migrants and nonmigrants in early life indicators (height and education) and to assess how these carly life characteristics are related to both migrant selectivity and later life health. We compare U.S.-born and foreign-born Mexican Americans living in the United States to persons residing in Mexico-some of whom once lived in the United States. More specifically, we examine the interrelationships between childhood health circumstances, as indexed by height, and education, nativity and migration, and late-life health in an effort to determine how migrants differ from the population al origin and destination. We also examine how height and migration status are related to late-life health.

Although migration is primarily motivated by economic factors, we hypothesize that the Mexican American population that is born in Mexico and migrates to the United States will be drawn from Mexicans who had belter childhood health relative to those who remain in Mexico, controlling for socioeconomic factors. In addition, we hypothesize that returning migrants to Mexico will have less lavorable charackeristics, both economic and health. compared to those who stay in the United States. We also expect that these early life conditions and migration status will continue to be related to later life health in both Mexico and the United States.

\section{BACKGROUND}

Health differences between native- and foreign-born populations have been observed not only in the United States but also in other countries (Marmot, Adelstein, and Bulusu, 1984; Khat and Darmon, 2003; Crimmins, Hayward, and Seeman, 2004; Jasso et al., 2004). Because migration from Mexico to the United States is concentrated in the early working ages and is most often motivated by the desire for better employment opportunities, migrants tend to be selected from healthier persons in a given SES group of the population of origin (Jasso et al., 2004). Traditional economic theory suggests that in a country with a high skill return, like Mexico, those with limited economic options are most likely to consider 
migration to the United States. Research has shown education to be unrelated to the probability of legal migration, but that undocumented immigrants have lower education levels than nonmigrants (Massey and Espinosa, 1997).

Migration occurs in both directions between the United States and Mexico. Return migration may have different causes than the initial migration. A common cause of return migration is likely to be disappointment in achieving economic gains. Among older migrants, health may also be an important cause of return migration (Palloni and Arias, 2004). Persons who become unhealthy may return to Mexico for either health treatment or familial support. One study has shown that cancer mortality among older foreign-born Hispanics in the United States is lower than would be expected, raising the possibility that this could be explained by return migration to Mexico of those with cancer (Crimmins, Hayward, and Seeman, 2004).

Persons born in Mexico who migrate to the United States should differ in health from Mexican Americans who were children in the United States because they have lived through very different childhood epidemiological environments. Persons raised in Mexico are more likely to have lived through childhoods that were nutritionally deprived with regular exposure to infection resulting in adverse longrun effects on late-life health (Martorell and Habicht, 1986; Finch and Crimmins, 2004; Crimmins and Finch, 2006). Infant and child mortality was much higher in Mexico throughout the last century and economic development was slower than in the United States. So although migrants from Mexico may have better health compared to others in the sending population with the same social status, they are expected to be worse off in both health and social status than persons born in the United States.

Infectious diseases and/or insufficient nutritional intake result in less growth during childhood and reduced adult height. Studies have demonstrated the effect of childhood illness and social and economic deprivation in childhood on adult height, and have provided justification for the use of height as a summary indicator of childhood health and social circumstances (Gunnell et al., 1996). Studies have also linked height to subsequent adult health providing evidence of a link between early- and late-life health (Arnesen and Forsdahl, 1985; Kuh and Ben-Shlomo, 1997; Blackwell, Hayward, and Crimmins, 2001; Peck, 1994). In general, being taller has been related to lower overall mortality in adulthood (Davey Smith et al., 2000; Song, Davey Smith, and Sung, 2003), fewer strokes (McCarron et al., 2000, 2001; Song et al., 2003), and lower risk of cardiovascular disease (Davey Smith et al., 2000; Gunnell et al., 2003). On the other hand, greater height is associated with a greater risk of cancer (Davey Smith et al., 2000; Gunnell et al., 2001; Lawlor et al., 2003).

\section{DATA}

For this article, we used data on persons 50 and over from nationally representative samples from the United States and Mexico: the first wave of the Mexican Health and Aging Survey (MHAS) and the National Health and Nutrition Examination Survey IV (NHANES IV) of the United States (http://www.cdc.gov/nchs/ about/major/nhanes/datalink.htm). MHAS is a prospective panel study representative of the Mexican population aged 50 and older and their spouses begun in 2001 (hup://www.mhas.pop.upenn.edu/english/ home.htm.). The subsample of MHAS used 
in this analysis included the approximately $20 \%$ of participants $(n=2,623)$ randomly selected for collection of anthropometric measures including height. Of this group, 358 participants did not have data on height because they refused, the measurement was missing, or it was not deemed safe to collect height. This resulted in a potential sample size for analysis of 2.265. Those excluded from the sample were more likely to be older, male, and have a higher level of education.

The NHANES sample is a cross-sectional sample of the noninstitutionalized population of the United States. It is particularly valuable for this analysis because the Hispanic sample is largely of Mexican American origin. NHANES IV data used in this study were collected from 1999 through 2002. Although NHANES data are collected for all ages and ethnic groups, the sample used here was limited to Mexican Americans age 50 and older ( $n=957)$ with a height measurement $(n=85())$. Persons with missing height data were older and more likely to be U.S.-born.

Combining MHAS and NHANES data allowed us to compare four categories of respondents: (a) Mexicans who had never lived and worked in the United States (MHAS, $n=2,051$ ), (b) Mexicans who had lived or worked in the United States and returned to Mexico (return migrants. MHAS, $n=214$ ), (c) Mexicans who had immigrated to the United States and remained there (Mexican immigrants, NHANES IV, $n=428$ ), and (d) U.S.-born Mexican Americans (NHANES IV, $n=422$ ). Return migrants from the United States to Mexico in MHAS were identified by the question "Not counting vacations and short visits, have you ever worked or lived in the U.S.?" In NHANES, Hispanics were self-identified as those who were born in, or had ancestors from, Spain or other Spanish-speaking countries in Central or South America including the Caribbean basin. Among Hispanics, those of Mexican birth or descent who identified themselves as Mexican, Mexican American, Chicano, or Tex-Mex were classified as Mexican Americans.

\section{MEASURES}

Table I displays descriptive slatistics for each of the four groups. The first two columns provide information from the MHAS respondents; columns 3 and 4 have information on the NHANES IV sample. Age and gender were included in all multivariate analyses of height and health to adjust for differences in the groups by age and gender. Age was included to control for secular trends in height; gender to control for malefemale differences. The mean age for all groups ranged from 61 to 64 years, with return migrants the oldest on average. Return migrants to Mexico were predominantly men $(80.5 \%)$. Women were less likely to be relurn migrants as they were more likely to migrate to join a man who had established a high probability of a long stay and some job security.

Respondent's education rellected early life SES. In the U.S. NHANES IV, data on education were only available in the three categories shown in Table 1. Mexican Americans had a much higher level of education than persons living in Mexico.

Trained examiners collected information on measured height in both surveys. Height was measured in a slanding position with the feet together without shoes. Health behaviors were included in analyses of health indicators for both countries. Current smoking status and heavy drinking were included as indicators of health risks. NHANES participants were coded as heavy drinkers if they reported an average of five 
TABLE 1

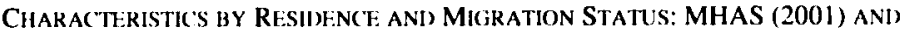
NHANES IV (1999-2002)

\begin{tabular}{|c|c|c|c|c|c|c|c|c|c|c|c|c|}
\hline & \multicolumn{6}{|c|}{ MIIAS $(200) 1)$} & \multicolumn{6}{|c|}{ NHANI:SIV (I9O) 20012$)$} \\
\hline & \multicolumn{3}{|c|}{$\begin{array}{c}\text { Mexicans } \\
\text { (Nonmigrants) }\end{array}$} & \multicolumn{3}{|c|}{$\begin{array}{c}\text { Return Migrants } \\
\text { to Mexico }\end{array}$} & \multicolumn{3}{|c|}{$\begin{array}{c}\text { Mexican } \\
\text { Immigrants to } \\
\text { United States }\end{array}$} & \multicolumn{3}{|c|}{$\begin{array}{l}\text { U.S.-born } \\
\text { Mexican } \\
\text { Americans }\end{array}$} \\
\hline & $M$ & $S D$ & $\%$ & $M$ & $S D$ & $\%$ & $M$ & sD & $\pi$ & $M$ & $S D$ & \% \\
\hline Height (cm) & 156.0 & 9.8 & & 162.3 & 9.8 & & 160.5 & 9.2 & & 16.3 .2 & 10.2 & \\
\hline Age (Years) & 62.7 & 10.0 & & 64.5 & 8.9 & & 60.7 & 8.5 & & 62.3 & 9.4 & \\
\hline Female & & & 57.6 & & & 19.5 & & & 52.7 & & & 53.8 \\
\hline \multicolumn{13}{|l|}{ Education (Years) } \\
\hline Mexico United States & & & & & & & & & & & & \\
\hline $0-4 \quad 0-11$ & & & 63.8 & & & 60.4 & & & 83.3 & & & 53.8 \\
\hline $5-8 \quad 12$ & & & 21.6 & & & 24.0 & & & 6.2 & & & 15.2 \\
\hline $13+$ & & & 14.7 & & & 15.5 & & & 10.5 & & & 31.0 \\
\hline Weight (kg) & 66.0 & 14.0 & & 69.5 & 12.3 & & 74.4 & 16.8 & & 77.2 & 18.1 & \\
\hline Current smoker & & & 17.4 & & & 25.7 & & & 12.2 & & & 18.9 \\
\hline Heavy drinker & & & 6.2 & & & 13.8 & & & 11.3 & & & 10.2 \\
\hline \multicolumn{13}{|l|}{ Self-reported } \\
\hline Hypertension & & & 39.8 & & & 28.1 & & & 33.6 & & & 43.1 \\
\hline Heant attack & & & 3.7 & & & 3.6 & & & 2.9 & & & 7.3 \\
\hline I Tiabetes & & & 17.8 & & & 10.9 & & & $21 . .3$ & & & 20.1 \\
\hline Stroke & & & 3.4 & & & 2.9 & & & 3.7 & & & 6.1 \\
\hline Poor health & & & 63.1 & & & 66.5 & & & 56.0 & & & 39.5 \\
\hline Functional difficulty ${ }^{a}$ & & & 9.9 & & & 11.1 & & & 23.4 & & & 27.7 \\
\hline \multicolumn{13}{|l|}{$\begin{array}{l}\text { Measured high risk or } \\
\text { taking medication }\end{array}$} \\
\hline Systolic blood pressure & & N/A & & & N/A & & & & 42.7 & & & 46.9 \\
\hline Total cholesterol & & $N / A$ & & & N/A & & & & 32.5 & & & 32.3 \\
\hline Glycated hemoglobin & & N/A & & & N/A & & & & 23.2 & & & 22.3 \\
\hline Health insurance & & & 52.2 & & & 51.5 & & & 60.7 & & & 88.6 \\
\hline
\end{tabular}

Note. - MHAS = Mexican Health and Aging Survey: NHANI:S = National Health and Nutrition Examinalion Survey. N/A = not available Difficulty in any one of the following five activities: eating. dressing, Iransferring, preparing a meal, and maniging money (only among those who had information in three or more items).

or more drinks per day when they consumed alcohol in the past year; MHAS participants were asked if they consumed five or more drinks per day on the days they drank over the last 3 months.

Current adult health status in both surveys was indicated by self-reports of global health status, presence of diseases, and functioning problems. Diseases included hypertension, heart attack, diabetes, and stroke. Self-reported global health status was coded into high and low with answers of "poor" and "fair" combined into low. Presence of a functioning problem was defined as having difficulty performing any of five activities of daily living (ADL) or instrumental activities of daily living (IADL) items available for both countries (eating, dressing, transferring, preparing a meal, and managing money). Difficulty was defined as having some or much difficulty or being unable to do an activity in the NHANES sample, whereas it was defined as having difficulty or can't do in the MHAS sample.

Self-reports of health conditions are likely to be imperfect assessments of health and are likely to vary across countries and 
subgroups of the population in their accuracy. Self-reports are likely to be influenced not just by health but also by interaction with the health care syslem, belief's about health, education, and standard of living (Thomas and Frankenberg, 2002). Information on availability of health insurance was included in analyses for both countries as the presence of insurance may be linked to the use of services and an increased likelihood of reporting conditions. We expected that given the differences in insurance availability along with the educational and socioeconomic differences between the two countries, people in the United States would be more likely to have health knowledge.

For the NHANES participants, additional information on measured indicators of risk for cardiovascular disease and diabetes was also included to provide more objective indicators of physiological status. Measured indicators avoid some of the problems of validity and reliability inherent in self-reports of disease. For our analyses, we included systolic blood pressure, total cholesterol, and glycated hemoglobin. All of these indicators have been linked to mortality and should serve as indicators of health status. Glycated hemoglobin provided an indicator of serum glucose and insulin processing over the previous 2 months that indicated a potential for developing diabeles; associations could thus be compared with self-reports of diabetes. In addition, it was useful to incorporate both self-reports of hypertension and measured blood pressure to see if the associations differed because of potential underreporting. Those with levels of these indicators that exceeded clinical guidelines for high risk or who were taking medication to control blood pressure, cholesterol, or blood sugar were defined as having values indicating elevated risk.

\section{METHODS}

We first examined the height of persons by residence in Mexico or the United States and migration status to assess diflerences between migrants and nonmigrants. Differences in height and education for migration groups were then examined using logistic regressions that control for gender and age to determine how migrants differ in terms of childhood health and social status. Then, to determine the association between height and migration and later life health, we used a logistic regression approach to examine associations between current health indicators and nativity, migration status, and height with controls for education, health hehaviors, and health insurance.

\section{RESULTS}

Figure 1 shows the distribution of height for four groups from the MHAS 2001 survey and the NHANES IV sample. Those living in the United States, U.S.-born and Mexican-born, were quite clearly taller than those living in Mexico, including both return migrants and those who never left. To examine the statistical significance of differences between migrants and nonmigrants with other factors controlled, we performed a series of regression analyses that allowed us 10 compare groups on height with controls for education, age, and gender (Table 2). The first analysis assessed the association between height and education and the likelihood of being an immigrant from Mexico living in the United States relative to a person living in Mexico who did not migrate. As expected, the odds ratios indicated that persons who were taller were more likely to have migrated to the United States. The relative likelihood of being an immigrant from Mexico to the United 


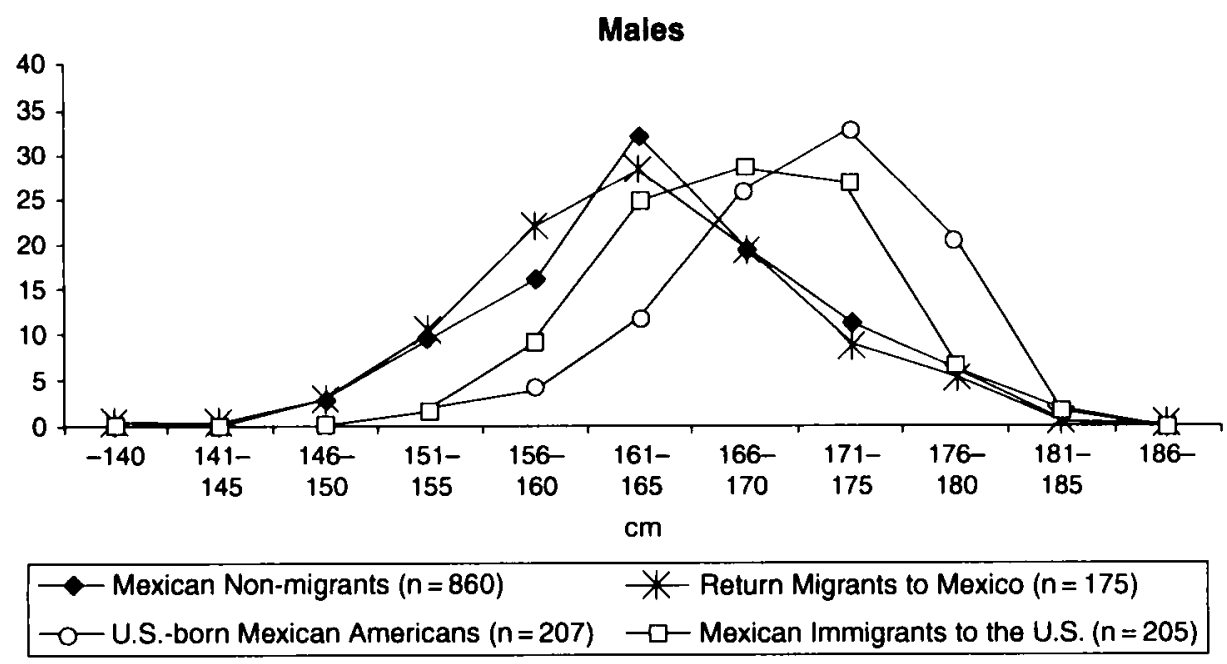

\section{Females}

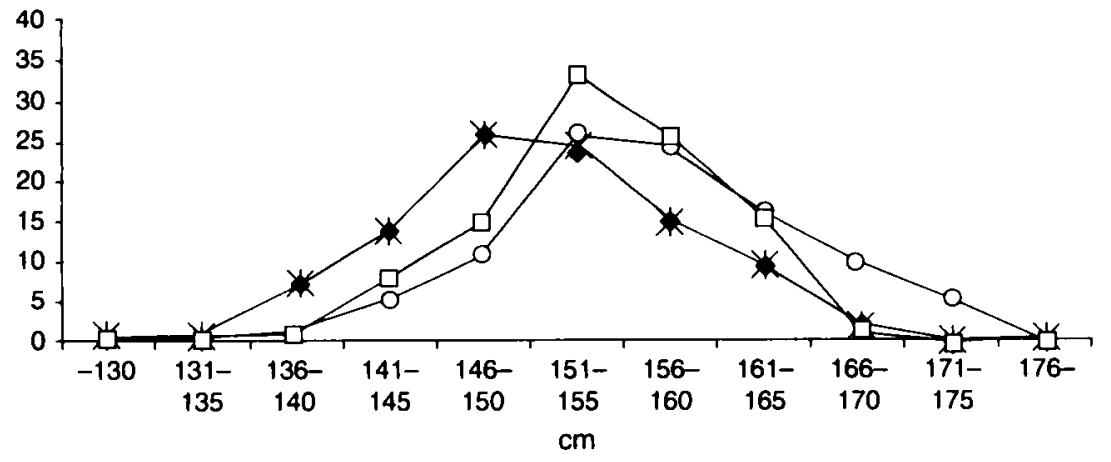

$\begin{array}{ll}- \text { Mexican Non-migrants }(n=1191) & \text { - Return Migrants to Mexico }(n=39) \\ -0-\text { U.S.-born Mexican Americans }(n=215) & -\square-\text { Mexican Immigrants to the U.S. }(n=223)\end{array}$

FIci. 1.-Percent distribution of height for persons ages 50 and older by residence and migration status (MHAS, NHANFS IV).

States increased $6 \%$ with each centimeter in height. Persons who had more or less than 12 years of education were less likely to become immigrants from Mexico to the United States than to stay in Mexico. These results suggest a selection process wherehy healthy as well as medium-educaled migrants are selected for migration.

As shown in Table 2, we compared return migrants to Mexico to immigrants who stayed in the United States. Return migration was significantly related to height but not to educational level. Return migrants to Mexico were shorter than immigrants who stay in the United States.

We also examined differences between groups residing in the United States to sec how migrants compare to the U.S.-born Mexican heritage group. The Mexicanborn were shorter than the U.S.-born; a 
TABLE 2

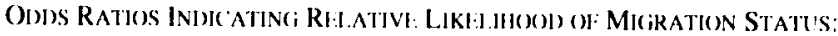
MHAS (2001) ANI NHANES IV (1999-2002)

\begin{tabular}{|c|c|c|c|}
\hline & $\begin{array}{c}\text { IMMLIRANI HOLNILI) } \\
\text { SIATIS WS MIXICAN } \\
\text { NONMIIIKANI } \\
\text { (OR }\end{array}$ & $\begin{array}{l}\text { RI IIIRN MIITANI VS. } \\
\text { IMMIGRANT WOUNITID } \\
\text { SIAIFS } \\
\text { OR }\end{array}$ & 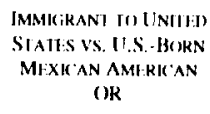 \\
\hline Age & $0.99 *$ & $1.05^{* * * * *}$ & $0.96 * * * *$ \\
\hline Female & $1.8 .3 * * * *$ & $0.13^{* * * *}$ & $0.41 * * * *$ \\
\hline \multicolumn{4}{|l|}{ Fducation' (Years) } \\
\hline Less than 12 & $0.24 * * * *$ & 0.85 & $3.99 * * * *$ \\
\hline More than 12 & $0.48^{* * *}$ & 0.8 .5 & 0.89 \\
\hline Height (continuous) & $1.06 * * * *$ & $0.96^{* *}$ & $0.94 * * * *$ \\
\hline$N$ & 2,477 & 642 & 850 \\
\hline
\end{tabular}

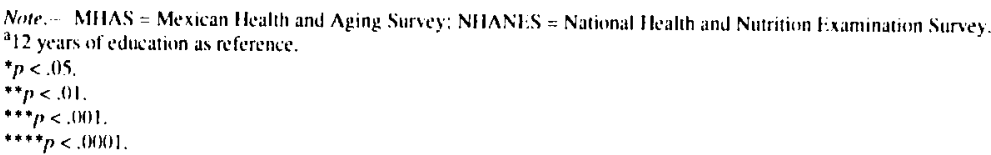

centimeter more of height was associated with a $6 \%$ reduced relative likelihood of being Mexican-born. Those with less than 12 years of education were more likely to be Mexican-born. So the Mexican-born group 50 and older was shorter and had less education than the Mexican American population into which it had immigrated.

Next, we turned to health differences in adulthood and examined the link between indicators of adult health status and height and migration status as well as education, health behaviors, and availability of health insurance in the United States (Table 3) and Mexico (Table 4). This allowed an assessment of the independent effects of height, nativity, and education. We separated the two samples because of the different health indicators available and because of likely differences in the accuracy of self-report of diseases. Because health is not only determined by childhood but also by current conditions, we also included indicators of current health behaviors so that uncontrolled differences in behaviors were not being attributed to other factors. We added variables to these models sequentially to examine changes in the relationship between migration and height and health indicators without education and the additional controls, but the results on prior variables changed very little with inclusion of additional variables, so we present only the final models with all variables included.

We found evidence that better childhood health is related to fewer health problems in later life among persons of Mexican herilage living in the United States (Table 3). Taller persons were less likely to have had a heart attack and less likely to have poor sellrated health, functioning problems, high measured systolic blood pressure, and high glycated hemoglobin. Nativity was also related to some indicators of health. Compared to Mexican Americans born in the United States, Mexican immigrants to the United States had lower hypertension, either self-reported or measured systolic blood pressure; however, they had worse selfreported health. We tested for an interaction between nativity and height and found no signilicant relationships. With controls for height and migration status, there were few relationships between education and health 


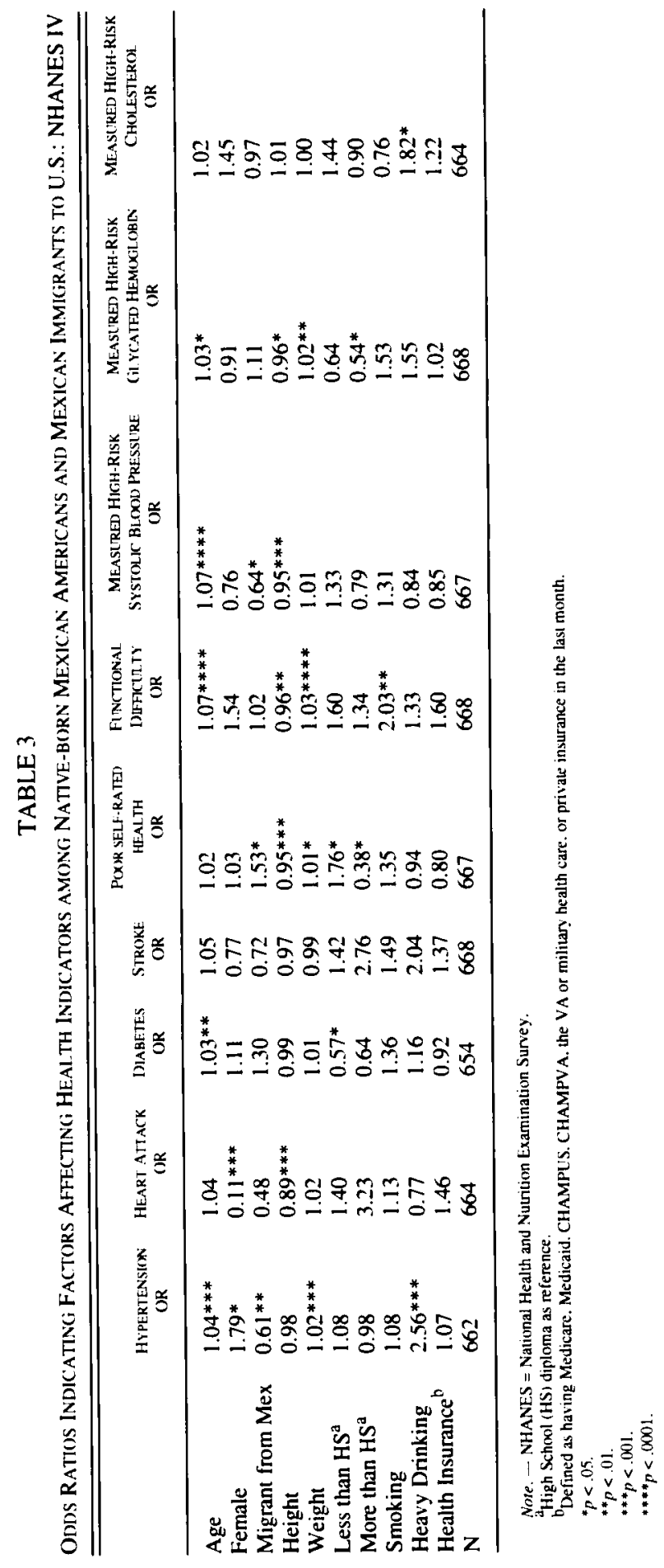


TABLE 4

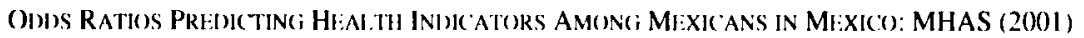

\begin{tabular}{|c|c|c|c|c|c|c|c|}
\hline & 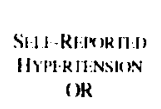 & 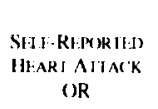 & 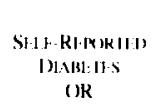 & 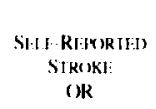 & $\begin{array}{c}\text { SFI - RF:MUTIFI) } \\
\text { (ANCTR } \\
\text { OR }\end{array}$ & $\begin{array}{c}\text { P(X)R } \\
\text { SHI-KAIH } \\
\text { HLAL.II } \\
\text { (WR }\end{array}$ & $\begin{array}{c}\text { JINCTKNAL } \\
\text { DIITITIY } \\
\text { OR }\end{array}$ \\
\hline Age & $1.03 * * * *$ & 0.97 & $0.98 * *$ & 0.99 & 1.00 & 1.01 & $1.06 * * * *$ \\
\hline Female & $1.47^{* *}$ & 0.68 & 1.11 & 0.99 & 1.57 & 1.06 & $2.07^{* *}$ \\
\hline Return migrant & $0.58 * *$ & 0.83 & 0.68 & 1.36 & 2.37 & 1.25 & 1.77 \\
\hline Height & 0.99 & 1.01 & 0.99 & 0.99 & 0.99 & $0.96 * * * *$ & $0.96^{* *}$ \\
\hline Weight & $1.0 .3 * * * *$ & 1.01 & $1.02 * *$ & $1.03 *$ & 1.01 & $\left.1.0\right|^{*}$ & $1.04 * * * *$ \\
\hline \multicolumn{8}{|l|}{$\begin{array}{l}\text { Education } \\
\text { (Years) }\end{array}$} \\
\hline $1-4$ & 1.15 & $0.45^{*}$ & $0.47 * * * *$ & $0.20^{* * * * *}$ & 0.54 & 1.15 & 0.75 \\
\hline $5-8$ & 0.86 & $0.10^{* * * *}$ & $0.56^{* *}$ & $0.19 * * *$ & 0.32 & $0.7 .3 *$ & $0.24 * * * *$ \\
\hline $9+$ & 0.72 & 0.65 & $0.19 * * * *$ & $0.05^{* *}$ & 1.41 & $0.28 * * * *$ & $0.08 * * * *$ \\
\hline $\begin{array}{l}\text { Current } \\
\text { smoking }\end{array}$ & $0.60^{* *}$ & 0.61 & 0.75 & 0.64 & 0.37 & 1.29 & 1.07 \\
\hline $\begin{array}{l}\text { Heavy } \\
\text { drinking }\end{array}$ & $0.59 *$ & 0.49 & $0.7 !$ & 0.48 & 0.56 & 0.99 & $2.64 * *$ \\
\hline $\begin{array}{l}\text { Health } \\
\text { insuranceb }\end{array}$ & $2.4 ! * * * *$ & $5.17^{* * * *}$ & $4.66^{* * * *}$ & $2.97^{* *}$ & 1.43 & $1.25 *$ & 1.34 \\
\hline$N$ & 1.792 & 1.795 & 1,791 & 1.794 & 1.796 & 1.821 & 1.821 \\
\hline
\end{tabular}

Nole. - MIIAS = Mexican Health and Aging Survey.

${ }^{2}$ No eduluation as reference.

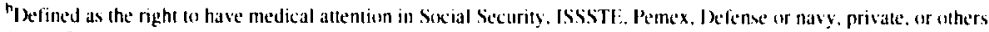

$* p<.165$.

$* * p<.01$.

$* * * p<.(0) 1$

$* * * *<<0001$

in this sample. Mexican Americans with low education were more likely to report poorer overall health, but they were less likely to report diabetes, and those with high education were less likely to have high glycated hemoglobin. One interpretation of these results could be that diabetics in the lowest education group have not survived; another is that there is a lower rate of diagnosis among those with less education.

In the population living in Mexico, taller height was related to better self-reported health and fewer functioning difficulties (Table 4). There is little evidence of health differences between return migrants and nonmigrants. Return migrants reported less hypertension than those who never migrated. Generally, those with more education reported fewer health problems than did those with no education. Having health insurance was positively related to higher self-reports of diseases and poorer self-rated health, suggesting that interaction with the health care system may increase the reporting of health problems.

\section{DISCUSSION AND CONCLUSIONS}

Recent research has suggested that reports of a Hispanic paradox, in which U.S. Hispanics have better-than-expected health based on their SES, may be due to selection forces working in migrants to and from the United States. To directly examine this question, it is necessary to use objective data on the health of both the sending and receiving populations, as well as data reflecting both pre- and postmigration health status. In this study, we used data drawn from Mexicans living in Mexico as well as Mexican 
immigrants to the United States and U.S.born Mexican Americans to examine the relationships between height and education, migration, and later life hcalth indicators.

We found support for the healthy migrant hypothesis that Mexican migrants to the United States are selected for greater height, or better childhood nutrition and health. Mexican immigrants are taller than persons of the same age living in Mexico who have never migrated. Our results suggest that migrants are selected on the basis of health as well as SES.

We also found some suppon for the returning-salmon hypothesis that return migrants to Mexico are also selected on the basis of height as return migrants are shorter than those who stay. However, we did not have an indicator of later life health that may affect the decisions of return migrants. We had only associations between current health and state of return migration. Return migrants generally had similar self-reported adult health to others living in Mexico, although they were less likely to report hypertension.

Additional comparisons between the U.S.-born Mexican Americans and Mexican immigrants to the United States show differences in early life health as indicated by height, as U.S.-born Mexican Americans are taller than migrants. U.S.-born Mexican Americans also have higher levels of education. However, using controls for early life conditions, education, health behaviors, and availability of health insurance, we found that Mexican immigrants to the United States have lower rates of measured and selfreported hypertension relative to U.S.born Mexican Americans and do not have higher levels of any adult health conditions.

Results point more generally to the importance of childhood health and social conditions as determinants of late-life health. Greater height is related to better self-rated health and fewer functioning difficulties in both Mexico and the United States. These two indicators may be the best indicators of health in this sample as they are less likely to be influenced by medical information than the other self-reports. In the United States, taller height is also related to lower prevalence of heart attack, measured hypertension, and high glycated hemoglohin. Education is related to health status in late life in both Mexico and the United States. Higher levels of education are protective against heart attack, diabetes, stroke, poor self-rated health, and functional difficulties in Mexico. In the United States, higher levels of education are related to better self-rated health and lower levels of glycated hemoglobin. Clearly, childhood experiences have important links to later life health indicators.

We used height as our indicator of childhood health circumstances. Although height is generally stable across adulthood, some shrinkage does occur at the oldest ages. For this reason, many analyses use leg length to index childhood health. Adult leg length, as well as height, is thought to be particularly sensitive to diet in early childhood given the rapidity of leg growth in this period (Leitch, 1951; Wadsworth et al., 2002). Longer leg length has also been related to lower risk of cardiovascular disease (Davey Smith et al., 2001; Gunnell et al., 2001, 2003; Lawlor el al., 2003). The MHAS survey and an earlier NHANES survey (National Center for Health Statistics, 1994) have information on lower leg length or knee height (for those 60 years of age and older) that can be used to investigate the similarity of our results when lower leg length is substituted for height. We repeated our analysis using lower leg length from NHANES III and limiting the analysis to those age 60 and older in MHAS (2001). Our results are similar but not identical. The distribution of lower leg length for those over age 60 by migration status 
indicates differences quite similar to those for height (Figure 2). When lower leg length is substituted for height in equations like those in Table 2, the results are quite similar. Immigrants to the United States have longer lower leg length relative to Mexicans who have not migrated, and return migrants have shorter lower legs than those who stay. Both of these point to a selection of migrants by health status. In contrast to the results for height in
Table 2, however, there is no significant difference in lower leg length between immigrants to the United States and U.S.-born Mexican Americans 60 years of age and older. It is possible that this result is due to analysis of a different time period and a different age group.

We have not considered age of migration up to this point, as it is not available in NHANES IV. But those who migrated as

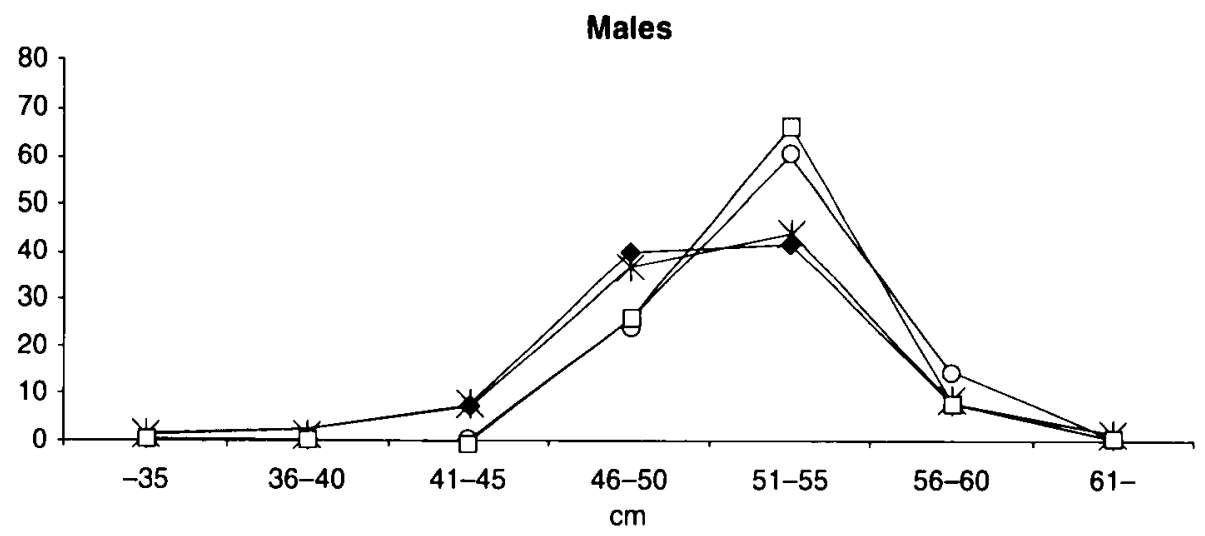

$\checkmark$ Mexican Non-migrants ( $n=448$ )

* Return Migrants to Mexico $(n=115)$

-O-U.S.-born Mexican Americans $(n=302)$

$-\square$-Mexican Immigrants to the U.S. $(n=182)$
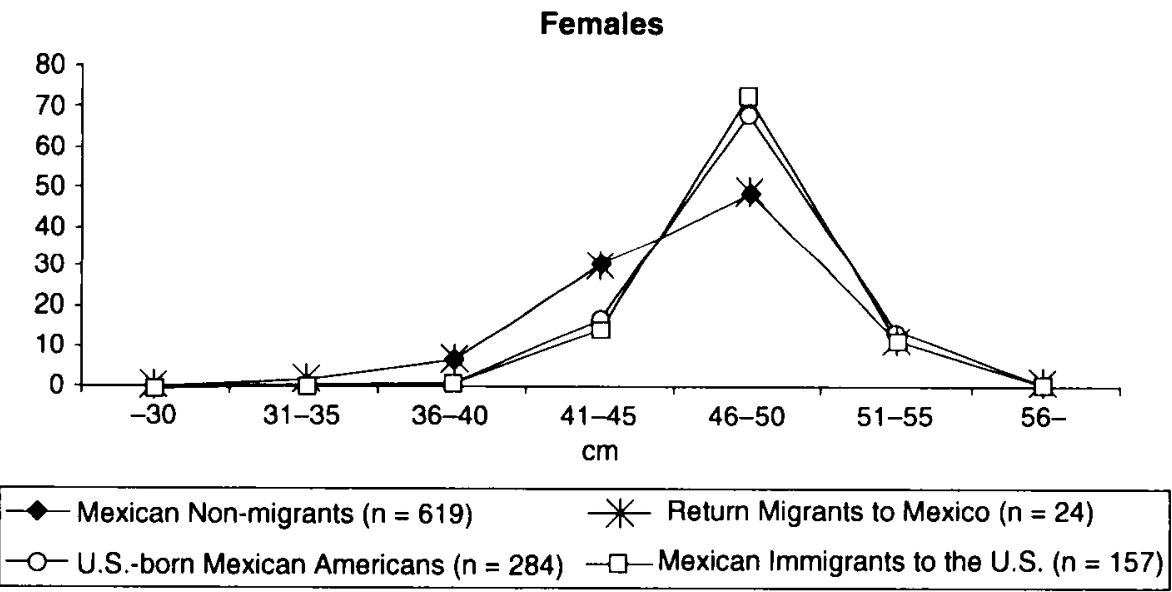

Fic. 2.-Percent Distribution of Lower Leg Length for Persons Ages 60 and over by Residence and Migration Status (MHAS, NHANFS III). 
children may actually have life circumstances more similar to native-born persons than foreign-born adult migrants. Migrants can be divided into younger (less than 15 years) and older groups in NHANES III. When only adult migrants are considered, the results are similar to those in Table 2, providing confidence that the differences between migrants and nonmigrants actually exist before migration.

There are several limitations to this study. First, self-reports of health conditions are likely to be differentially inaccurate in the two countries given the survey differences in reported prevalence of diseases, functioning problems, and poor health as well as the positive relationship between availability of heath care and reported health problems. In the United States where we had measured high blood pressure as well as self-reports of hypertension, associations between independent variables and both of these indicators of hypertension were similar, leading to some confidence in self-reports in the United States. In the future, the utilization of additional methods of measuring health indicators such as performance measures of functioning and biological data would improve comparability across surveys as well as providing more valid measurement within samples.

Another limitation of our analysis is the lack of detailed education information in
NHANES IV. With more detail on education and a different specification of this variable, the results might better specify educational differences at the low levels of education characteristic of this immigrant population. Finally, there are limitations in our characterization of the migrant groups. Although we defined four groups of migrants as the basis of our analysis, the group of nonmigrants in Mexico may provide an imperfect comparison group as it is a composite of those who have too few skills and too many opportunities to consider migration. In addition, undocumented migrants to the United States may not participate fully in NHANES, leaving the immigrant group nonrepresentative of this group.

In spite of these limitations, this article provides evidence consistent with health selectivity of migrants to the United States and provides further evidence of links between early life conditions and late-life health for persons in a variety of early-and late-life conditions.

\section{ACKNOWLEDGMENTS}

Support for this project was provided by the National Institutes of Health (NIH), Grants R0I AG 1801. P30 AG17265, P30 AG12836, R01 AG023347, R01 AG1846, and T32 AG00037.

\section{REFERENCES}

AbHaI(x)-LaNZA. A. F., B. P. DOHRLNWINI), D. S. N(;MAK, et al., 1999. The Latino mortality paradox: A test of the "salmon bias" and healthy migrant hypotheses. Anver. J. Public Health 89:1543-1548.

ARNESEN, E., and A. ForSIAHI., 1985. The Tromso heart study: Coronary risk factors and their association with living conditions during childhood. J. Epidemiol. Community Health 29:210-214.

BlackWHI1, D., M. D. HAYWARI), and E. M. CRIMMINS. 2001. Does childhood health affect chronic morbidity in later life? Soc. Sci. Med. 52:1269-1284.

Сho, Y., W. P. Frisbis: and R. Rocifks, 2004. Nativity, duration of residence, and the health of
Hispanic adults in the United States. Int. Migration Rev. 38: 184-211.

Crimmins, E. M., and C. Finch, 2006. Infection, inflammation, height, and longevity. Proc. Natl. Acad. Sci. 103:498-503.

Crimmins, E. M., M. D. HaywakI), and T. E. Shiman, 2004. Race/ethnicity, socioeconomic status and health, p. 310-352, In N. ANIDI:RSON, R. BUI.ATU, and $B$. Conite (eds.) Critical perspectives on racial and ethnic differences in health in late life. National Academies Press, Washington, D.C.

Daviy Smith, G., R. GRHENW(O)I, D. GINnNEI., et al., 2001. Leg length, insulin, resistance, and 
coronary heart disease risk: The Caterphilly study. J. Epidemiol. Community Health 55:867-872.

DAVEY Smith, G., C. HART, M. Urton, et al., 200(1. Height and risk of death among men and women: Aetiological implications of associations with cardiorespiratory disease and cancer monality. J. Fipidemiol. Community Health 54:97-103.

Ejo, I. T., C. M. TURRA, B. Kh:SThenbalim, et al., 2004. Mortality among elderly Hispanics in the United States: Past evidence and new results. Demography 41 : 109-128.

Finch, C., E. M. Crimmins, 2004. Inflammatory exposure and historical changes in human lifespans. Science 305:17.36-17.39

GinNil.I. D., 2(0)2. Commentary: Can adult anthropometry be used as a 'biomarker' for prenatal and childhood exposures? Int. J. Epidemiol. 31:390-394.

Ginni:i.t, D., S. Frankfi., K. Nancilahal. et al., 1996. Lifecourse exposure and later disease: A follow-up study based on a survey of family diet and health in pre-war Britain (1937-1939). Public Health 110:85-94.

Gunnil.t, D., M. Okasha, G. Davey Smith, el al., 2001. Height, leg length and cancer risk: A systematic review. Epidemiol. Rev. 23:313-342.

GuNNIII., D., E. WhITI.FY, M. UPTon, et al., 2003. Associations of height, leg length and lung function with cardiovascular risk factors in the Midspan fanily study. J. Epidemiol. Community Health 57:141-146.

JASSO, G., D. S. MASsYY, M. R. RosinzWEJci, et al., 2004. Immigrant health: Selectivity and acculturation, p. 227-268, in N. ANIJERSON, R. BUI.ATO, and $B$. Comlen (eds.). Critical perspectives on racial and ethnic differences in health in late life. National Academies Press. Washington. D.C.

KHAT, M., and N. DARMON, 2003. Is there a Mediterranean migrants mortality paradox in Europe'? Int. J. Fipidemiol. 32:1115-1118.

KLH, D., and B. BEN-SH.OMO, 1997. A life course approach to chronic disease epidemiology. Oxford University Press, Oxford. England.

LAWLOR, D. A., M. OKaSha. D. GinNEJ., et al., 2003. Associations of adult measures of childhood growth with breast cancer: Findings from the British women's heart and health study. Br. J. Cancer 89:81-87.

Li:TT'H, I., 1951. Growth and health. Br. J. Nutr. 5:142-151.

MarmoT, M. G., A. M. AIr.I.STtEIN, and L. But.ust, 1984. Lessons from the study of immigrant mortality. Lancet $1: 1455-1457$.

MARToRJill, R., and J. P. HABICHT, 1986. Growth in early childhood in developing countries, $p$. 241-262, $\ln$ F. FAll. KN]:R and J. M. TANNI:R (eds.) Human growth: A comprehensive treatise. Plenum Press, New York

MASSI:Y, D, S., and K. E. ESIINOSA, 1997. What's driving U.S.-Mexico migration? A theoretical. empirical, and policy analysis. Amer. J. Sociol. 102:939-999.

McCarkon, P. C., R. Grienw(x), S. Fbrahilm, et al., 2000. Adult height is inversely associaled with ischaemic stroke. The Caemphilly and Speedwell collaborative studies. J. Epidemiol. Community Health 54:239-240.

Mi Carkon, P. C., C. L. Hart, D. Holl, el al., 2(X)1. The relation between adult height and hatemorthagic and ischaemic stroke in the Renfrew/Paisley study. J. Fipidemiol. Community Health 55:404 405.

Mr:XIC'AN Heal.TH anI) A(ilNe; Survi:y (MHAS), 2001 . Retrieved from http:/www.mhas.pop.upenn. edu/english/home.htm.

National. Centrir for Hial.Th Statistic's, 1994. Plan and operation of the third National Health and Nutrition Examination Survey, 1988-94. Vital Health Stat. 1(32).

NATIONAI. HI:AITHI ANI NUTRITION FXAMINATION St'RVI:Y (NHANFS), 1999-2000, 2001-2002. Retrieved from http://www.edc.gov/nchs/aboul major/nhanes/datalink.htm.

PAIJoNI. A.. and E. ARIAS, 2004. Paradox lost: Explaining the Hispanic adult mortality advantage. Demography 41:385-415.

PAIJON, A., and D). C. FWIBANK, 2004. Selection processes in the study of racial and ethnic differentials in adult health mortality, p. 17I-226, In N. ANI):RSON. R. BU1.ATO, and B. ColliN (eds.) Critical perspectives on racial and ethnic differences in health in late life. National Academies Press: Washington, D.C.

PAIIONI, A., and J. D. MORINOFF, 2001. Interpreting the paradoxical in the Hispanic paradox. Ann. N.Y. Acad. Sci. 954:140-174.

PFC'K. M. N., 1994. The importance of childhood socioeconomic group for adult health. Soc. Sci. Med. 39:553-562.

RAMIRI:Z, R. R., and P. G. II: I.A CRIIZ, 2003. The Hispanic population in the United States: March 2002, p. 20-545, In Current population reports. U.S. Census Bureau. Washington, D.C.

Sincih, G. K.. and B. A. Mil.t.t., 2004. Health, life expectancy, and mortality patterns among immigrant populations in the United States. Revue Canadienne De Sante Publique 95:14-21.

Sonci, Y. M.. G. DAVIYY SMITH, and J. SING, 2003. Adult height and cause-specific mortality: A large prospective study of Korean men. Aner. J. Epidemiol. 158:479 485.

SorI.IL, P. D)., E. BA('KI.l NI), N. J. Johnson, et al., 1993. Mortality by Hispanic status in the United States. J. Amer. Med. Assn. 270:2464-2468.

TuOMAS, D., and F. Frankinisi:R(i, 2002. The measurement and interpretation of health in social surveys, p. 387-420, In C. MI:RRAY, J. SAlomon, C. MAtulirs, et al. (eds.) Summary measures of population health. World Health Organization, Geneva. Switzerland.

U.S. CI:NSUS BL'RI:AI, n.d. Demographic profiles. Table DP-1. Profile of general demographic characteristics: 2000 . Retrieved August 30, 2005, from http://censtats.census gov/data/US/01000.pli

Walsworth, M., R. HARI)Y, A. PAll.. et al., 2002. Leg and trunk length at 43 years in relation to childhood health. diet and family circumstances: Evidence from the 1946 national birth cohort. Int. J. H.pidemiol. 31:38.3-390. 